\title{
O Sujeito e a Fala em Psicopatologia: Aportes Sobre a Foraclusão
}

\section{The Subject and the Speech in Psychopathology: Intakes About the Foreclosure}

\section{EI Sujeto y el Habla en Psicopatología: Aportes Sobre la Forclusión}

\section{Ricardo Bertazzo Ghilardi*}

Universidade Federal do Rio Grande do Sul - UFRGS, Porto Alegre, Rio Grande do Sul, Brasil

\section{Marta Regina de Leão D'Agord**}

Universidade Federal do Rio Grande do Sul - UFRGS, Porto Alegre, Rio Grande do Sul, Brasil

\begin{abstract}
RESUMO
Neste trabalho apresentamos uma contribuição ao estudo da especificidade da escuta psicanalítica na prática clínica. Iniciamos com uma análise histórica do termo foraclusão e da leitura que Lacan fez da concepção freudiana do processo de Verwerfung. Interessa mostrar a aproximação entre o sujeito foracluído da ciência, a constituição do sujeito na fala e o modelo topológico do corte. Trata-se de indagar sobre a estrutura na qual o sujeito está simbolicamente representado, e na qual, ao mesmo tempo, ele faz parte. Nesse sentido, o termo indiscriminado sujet responde tanto ao uso gramatical quanto ao topológico. Trabalhamos através de um caso clínico a diferença entre uma clínica do fenômeno e uma clínica da escuta, cujo efeito é um sujeito.
\end{abstract}

Palavras-chave: sujeito, sujet, foraclusão, clínica, psicanálise.

\section{ABSTRACT}

In this work we present a contribution to the study of the specificity of the psychoanalytical listening in clinical practice. We begin with a historical analysis of the term "forclusion" [rejection] and Lacan's interpretation of the freudian concept of the process of Verwerfung. This article deals with the relation among the rejected subject of the science, the constitution of the subject in speech and the topological model of the cut. We inquire about the structure in which the subject is symbolically represented and, at the same time, it is part of. In this way, the indiscriminate term sujet recovers both the grammatical and topological use. Through a clinical case we work the differences between a clinical practice of the phenomenon and a clinical practice of listening whose effect is a subject.

Keywords: subject, sujet, foreclosure, clinic, psychoanalysis. 


\begin{abstract}
RESUMEN
En este trabajo presentamos una contribución al estudio de la especificidad de la escucha psicoanalítica en la práctica clínica. Iniciamos con un análisis histórico del término forclusión y de la lectura que hace Lacan de la concepción freudiana del proceso de Verwerfung. Nos interesa mostrar la aproximación entre el sujeto forcluído de la ciencia, la constitución del sujeto en el habla y el modelo topológico del corte. Tratamos de indagar sobre la estructura en la que el sujeto se encuentra simbólicamente representado y, de la que, al mismo tiempo, es parte. En este sentido, el término indiscriminado sujet responde tanto al uso gramatical como al topológico. Trabajamos a través de un caso clínico, la diferencia entre una clínica del fenómeno y una clínica de la escucha, cuyo efecto es el sujeto.
\end{abstract}

Palabras-clave: sujeto, sujet, forclusión, clínica, psicoanálisis.

\title{
1 Introdução
}

A escuta clínica psicanalítica proporciona apontamentos substanciais para o campo das psicopatologias. As particularidades desta escuta contrastam com outras modalidades de abordagem das doenças e dos fenômenos do psiquismo, como a psiquiátrica e a psicológica. Entende-se que estabelecer um diálogo entre estas diferentes áreas, explicitando as diferenças que as fazem operar é importante para avançar nas pesquisas em psicopatologia. Neste artigo apontaremos um elemento proveniente diretamente da teoria psicanalítica para sustentar este diálogo, concernente à forma de abordagem destas doenças e dos "sinais" que ocorrem a um sujeito em sofrimento psíquico e nas ferramentas de entendimento destes sinais por parte de quem os escuta.

Jacques Lacan nos fornece um importante conceito: a foraclusão, e, mais especificamente, a foraclusão do sujeito no âmbito da ciência moderna. Através desse conceito, podemos obter esclarecimentos a respeito de uma abordagem de tratamento que escuta o sujeito que fala pelo sintoma e outra que aborda o sintoma de que se queixa o paciente.

Este termo, foraclusão, inicialmente foi utilizado por Lacan para se referir à diferença estrutural entre as neuroses e as psicoses, como uma contribuição à teoria freudiana. Em seguida, passou a ser utilizado como um operador em oposição à noção, também freudiana, de Bejahung. A noção de Bejahung foi traduzida teoricamente por Lacan como acolhida simbólica do significante primordial. Lemos isto ao longo de todo seu seminário dedicado ao tema das psicoses (Lacan, 1955/1956). Trata-se, portanto, de uma lógica de inclusão ou exclusão daquilo que cria e deixa marcas em um campo de atuação simbólica. Podemos incluir: tanto psicanalítico quanto psicológico ou psiquiátrico. Ou seja, todo campo simbólico se forma através do procedimento de inclusão ou exclusão de um elemento fundamental. Neste caso, propriamente, o sujeito. 
Esta é a tese que pode ser lida em "A ciência e a verdade" na afirmação de Lacan (1965/1966) de que "o sujeito sobre quem operamos em psicanálise só pode ser o sujeito da ciência" (Lacan, 1966/1998a, p. 873), de onde o mesmo está em uma "exclusão interna ao seu objeto" (p. 875). Se o sujeito sobre quem se opera é o mesmo, não o é com a mesma abordagem. Na ciência moderna, incluindo a ciência médica e psicológica, opera-se uma foraclusão do sujeito do campo da experiência. Seu saber não é considerado, pois pode ser uma ilusão, um equívoco, um saber ingênuo: seu saber sobre si não importa à ciência, seja o que tem a dizer, seja o que pode transmitir a quem o escuta. Mesmo Lacan tendo jamais mencionado diretamente o termo foraclusão referente ao sujeito na ciência moderna, pode-se entendera foraclusão como efeito da exclusão radical do mesmo sujeito em seu advento na ciência. Em "Resposta ao comentário de Jean Hyppolite sobre a Verneinung de Freud" (Lacan, 1966/1998b, p. 389) pode-se ler que "a Verwerfung constitui como tal isto que é expulso". Nota-se que, neste escrito, Lacan já se vale do termo foraclusão para a tradução do termo em alemão Verwerfung.

Através de um caso clínico, precisaremos a diferença entre a clínica que foraclui o sujeito e aquela que restitui este sujeito através da escuta, o qual insiste em surgir como cota residual da delimitação simbólica que o foraclui.

\section{Sobre a Foraclusão}

A primeira abordagem de Lacan do termo foraclusão ocorre na lição de 4 de julho de 1956, do Seminário sobre as Psicoses. Tratava-se, para Lacan (1955/1956), de buscar uma tradução para o termo alemão Verwerfung utilizado por Freud (1918/2006a, 1925/2006b) para indicar uma "exclusão" total de uma representação nociva ao Eu: a castração. Se no primeiro contato do sujeito com a representação da castração esta representação é inscrita no psiquismo, marcando o registro simbólico com a falta referida à castração, então se diz que ocorre a Bejahung. Se esta representação da castração é abolida do psiquismo, não se inscrevendo no registro simbólico, ocorre a foraclusão da representação da castração, para a qual o sujeito não terá mais acesso via registro simbólico. Esta representação fica restrita ao registro do Real.

Decorre desta construção a modificação do termo Verwerfung, primeiramente traduzido por "exclusão", para foraclusão, pois o primeiro termo não dava conta de um processo de exclusão radical, pelo qual algo nunca é inscrito no psiquismo. Segundo a interpretação de Lacan, "o processo de que se trata aqui sob o nome de Verwerfung (...) trata-se exatamente do que se opõe à Bejahung 
primária e constitui como tal aquilo que é expulso" (Lacan, 1998b, p. 389), ou seja, há no princípio inaugural de qualquer registro simbólico a Bejahung, acolhida, ou foraclusão, exclusão radical da significação da castração.

A significação da castração no registro simbólico é importante para marcar o lugar de uma falta, no sentido lógico de uma incompletude de qualquer sistema de representação simbólica. Havendo a inscrição (Bejahung) desta falta referente à castração, atuamos no campo das neuroses sob a defesa psíquica do recalque. Não havendo tal inscrição, pela defesa da foraclusão, a significação da falta não se insere no registro Simbólico. Mas a falta persiste como uma falta (furo) bruta, sem significação, e atua no registro do Real. Atuando desde o Real, a significação da castração se impõe ao sujeito como impossível, irrepresentável, sem nada que lhe faça menção.

No entanto, este mecanismo de inscrição e exclusão, de Bejahung e foraclusão na origem do aparelho psíquico, evolui na obra de Lacan para ser um operador de toda criação de um registro de atuação simbólica: todo registro simbólico que encerra o funcionamento de determinada teoria ou prática. Este é um momento importante no ensino de Lacan, pois situa toda a prática científica moderna, póscartesiana, em um registro de exclusão para a criação de um campo onde a significação da falta não responda. Um campo onde a castração não opere.

Em "A ciência e a verdade", Lacan (1966/1998a) amplia o uso do conceito de foraclusão para o de operador de uma exclusão propriamente dita. De forma que, em relação à ciência moderna, aquela inaugurada pelo cogito cartesiano que reduz o ser ao pensamento, "O sujeito está, se nos permitem dizê-lo, em uma exclusão interna a seu objeto" (Lacan, 1966/1998a, p. 875).

Através de Descartes, inaugura-se uma nova forma de relação com a verdade, independente da verdade divina, livre, eterna e infinita. O campo da ciência, por ser finito e apreensível, requer um método. Em um mundo pré-científico o homem se reconhece através da referência divina ao mundo. Com o isolamento divino referido por Descartes, "o sujeito da ciência vai então se definir em termos negativos" (Chemama, 2000, p. 8-9) ${ }^{1}$, pois "é um sujeito que não está à imagem do mundo, um sujeito que não se reconhece no mundo" (Chemama, 2000, p. 9) ${ }^{2}$. Ou seja, o homem não vive mais no mundo da sabedoria divina, mas no mundo do saber científico, como sujeito da ciência. Ou seja, há algo encoberto, que não se dá a ver senão pelo método cientifico, independente das percepções, que podem ser enganosas. O sujeito agora dependerá de instrumentos lógicos e científicos que fazem a mediação, mas o saber, enquanto experiência sensível será dispensável.

O que se abala nesta mudança é a questão da verdade, que passa da visão pré-científica como uma verdade ilógica, à razão de Deus, para 
uma verdade lógica, à razão do conhecimento humano, a sabedoria, de onde seu sujeito é expulso, foracluído.

Como operador da ciência moderna, a exclusão do sujeito é précondição para situar a verdade como uma entidade terceira ao sujeito e, sendo terceira, ela atesta sua condição de existência (a verdade existe). O que se toma, para seu advento, é então a foraclusão do sujeito no campo ciência moderna, sua experiência e seu saber sobre si e sobre o mundo, em exclusão interna a seu objeto.

Como efeito da foraclusão do sujeito na ciência dita moderna, o que o sujeito tem a dizer, seu conhecimento histórico e cultural não conta para a constituição da verdade do ser nem para a sua realidade. A ciência moderna, sem sujeito, controla o regime interno da verdade, através de seu método de investigação. Notamos que, através deste mecanismo de formação e "comprovação" da verdade pode-se estabelecer o que seria um discurso válido, inválido ou mesmo delirante. Ou seja, a verdade, o que se comprova cientificamente, atuaria ativamente na construção fantasmática, individual, da realidade na modernidade.

Nas disciplinas que se orientam desde o método científico, como a psiquiatria médica e a psicologia, notamos as particularidades iminentes ao que se exclui do campo de investigação que constitui tal clínica. Na psicanálise, prática que reintroduz o sujeito como operador da verdade, a escuta do sujeito direciona a aportes importantes nos tratamentos e na psicopatologia.

Para isto, apontamos em um breve relato de caso escutado desde a psicanálise durante alguns anos, depois de um longo período de tratamento psiquiátrico e farmacológico, as particularidades de cada abordagem de escuta clínica. Neste caso podemos esclarecer o que seria da ordem do retorno do sujeito proposto pela psicanálise.

\section{Construção a Partir de um Caso}

Uma mulher cujos sintomas são automutilações graves em diferentes partes do corpo, além de abertura de suturas cirúrgicas e impedimento de correta cicatrização das mesmas, entrega-se voluntariamente aos cuidados profissionais e familiares e é complacente com frequentes internações em hospitais psiquiátricos, onde recebe fortes medicações que a deixam em condição de invalidez. Além deste sintoma mais evidente, expresso nas automutilações, observa-se um quadro característico de inaptidão social, isolamento, compulsão alimentar, forte dependência parental, comportamentos esquizoides e a completa repulsa ao que é da ordem do sexual. Uma gravidez na adolescência teria originado a insígnia familiar de "estuprada". Desde então, sua atitude em relação ao 
próprio corpo poderia ser descrita como ciclos de automutilações, autodepreciações e queixas permanentes.

Dentro deste quadro descritivo, o que se pode escutar? Uma clínica fundamentada na descrição nosográfica dos fenômenos e preocupada com a eliminação dos sintomas, localizara esse comportamento num quadro de psicose. Além disso, a forma como os sintomas eram expressos no corpo convocava o olhar de quem a recebia em tratamento. Assim, instalava-se uma clínica baseada na ocorrência de fenômenos catalogados e descritos nosograficamente em um quadro esquizoide. Levando-se em conta apenas os sintomas aparentes e administrando medicações, as ocorrências subjetivas eram caladas ou não levadas em consideração: nada se escutava, além do que não estivesse delimitado dentro de um catálogo descritivo de fenômenos que a submetiam, por consequência do diagnóstico, a um tratamento de psicose.

Foi posteriormente a uma internação hospitalar que teve inicio o tratamento psicanalítico, onde a escuta clínica precisava se manter isenta à exibição e frequentes referências a atos de automutilação, de prazer envolvido, dor, carne, cor vermelha da pele, ardência e calor, sendo significantes constantes: o que estava para além do que os fenômenos davam a ver, mesmo catalogados e indicando um quadro de psicose ou estrutura de borda? O que insistia em aparecer exigindo, no sintoma, uma eterna relação entre o sujeito e o corte no corpo como marca de um estupro?

O tratamento psiquiátrico, atuando no impedimento da automutilação compulsiva, desconsiderava uma possível significação deste comportamento. A escuta psicanalítica produziu uma ruptura na lógica que sustentava o enlace do tratamento através destes sintomas. Se até então o que importava era mostrar as feridas, quando o olhar foi substituído pelo escutar, ocorreu um deslocamento da posição subjetiva.

Escutar o sujeito é apostar na perda que o constitui; algo da ordem do desconhecido, do não-saber: escutar o que não se encontra de antemão, mas que pode emergir como verdade alhures desde uma leitura que não encerre as possibilidades de emergência do sujeito, que admita sua emergência e que não o exclua a priori.

A reintrodução do sujeito, foracluído do discurso da ciência, é o principal questionamento que a escuta psicanalítica possibilita às outras abordagens que se dedicam ao tratamento do sofrimento psíquico. Mas o que seria escutar a fala deste sujeito que a psicanálise reinsere na busca pela verdade? 


\section{A Fala e o Sujeito}

Desde Lacan, sabemos que a única possibilidade de aceder a uma verdade sobre o sujeito seria através das construções de sua fala. É dizer, que o sujeito seria fruto de sua relação entre significantes, onde se representaria entre um e outro, advindo principalmente nas formações vacilantes da fala, além da linguagem usual.

$\mathrm{Na}$ língua francesa encontramos uma variação muito particular na palavra sujet. Percebemos que, além de referir um sujeito objetivo da ação ou da fala, também admite ser o conteúdo ou tema daquilo de que é falado, o assunto daquilo de que se fala. Neste sentido, Lacan indica-nos uma leitura interessante desta diferença em "Subversão do sujeito e dialética do desejo" (1998c) da qual vamos nos servir para apontar o que de fato escuta o psicanalista em relação ao psiquiatra. Nesse texto, Lacan retoma um trabalho significativo de Damourette e Pichon (1938) na construção da tese sobre o significante e nas particularidades do ser falante. Edouard Pichon, psicanalista que fez parte da primeira geração francesa de psicanalistas, recolheu na língua francesa uma distinção psicolinguística, entre a pessoa tenuee a pessoa etoffée.

para reavivar a metáfora de Damourette e Pichon sobre o eu gramatical, aplicando-a a um sujeito que a ela se destina melhor, que o fantasma é propriamente o "étoffe" daquele [Eu] que é propriamente recalcado, por ser só indicável no fading da enunciação. (Lacan, 1998c, p. 831)

A metáfora de Damourette e Pichon, referida por Lacan, está em Grammaire et Inconscient (1938). Na língua francesa, junto ao verbo, há duas posições dos pronomes pessoais. Os pronomes átonos, que se aglutinam ao verbo e referenciam a pessoa, je, tu, il/elle, e os pronomes independentes do verbo, moi, toi, lui/elle. A diferença entre estes dois tipos de pronomes seria uma significação psicológica e é isso o que Damourette e Pichon pretendem apresentar.

Os pronomes aglutináveis exprimem a pessoa tenue, que é reduzida a seu papel de pessoa gramatical. Ela é a entidade que produz a fala e que está sempre representada nesta fala, referindo-se diretamente a uma segunda ou terceira pessoa, ou mesmo à primeira pessoa. Já os pronomes posicionados de forma independente exprimem a pessoa étoffée, que pelo contrário exprime a noção de uma personalidade concreta completa, munida de caracteres essenciais e acessórios. Por ser independente do verbo, possibilita uma significação além da estritamente gramatical, sendo uma complementaridade dependente da enunciação, isto é, da fala, do contexto de quem está falando, portanto além do enunciado. A pessoa étoffée carrega a dimensão de algo além da representação 
gramatical e conjuga enunciação e enunciado, enquanto a pessoa tenue está presente em todas as cenas, reduzida à gramática. Assim, Pichon afirma que "a pessoa étoffée moi é então suscetível, - ponto capital para nós -, de aparecer como uma constelação complexa de onde o je seja extraível" (Damourette e Pichon, 1938, p. 64) ${ }^{3}$.

A ambiguidade do termo sujet na língua de Lacan encontra na dimensão étoffée da pessoa o princípio do sujeito da psicanálise que retorna e insiste em aparecer. Assim, sujet designa o sujeito barrado do inconsciente, dividido entre verdade e saber, mas também indica uma noção outra que é "daquilo de que se trata": sujet como objeto de um acontecimento, assunto, tema, motivo ou razão. Nossa proposta é operar com esta vacilação. Ou seja, com a condição de que o sujet para Lacan é também aquele que vai além do significante vacilante que representa o sujeito para outro significante. Referenciado pela dimensão étoffée, a significação do sujeito falante abre o campo do sentido para além do sujeito tenue, pessoa gramatical que está completamente representada. Em situação de tratamento psicanalítico, a escuta do como se diz pode produzir uma abertura para outras posições do sujeito.

Este sujeito étoffée, além de ser o sujeito que se apresenta conjugando enunciado e enunciação, também é aquele possível de se falar sobre. Aquele de quem se fala, é falado, é representado em outra instância, "desde o fora", mas que também se faz sujeito em reconhecimento àquilo que diz de seu universo simbólico, desde si mesmo. E aqui abre-se a possibilidade de pensarmos o sujeito que se produz étoffée como aquele que fala e se dirige a outra pessoa, ao psicanalista. É dizer, aquele sujeito que estabelece o laço transferencial. Já o sujeito tenue, pode-se dizer, ainda está sozinho, não se articula com o Outro em uma dimensão inconsciente, para além da linguagem. É dizer, não é tocado (ainda) pela transferência.

O que temos então é o que se aproximaria de uma dualidade, tenueétoffée, sujeito-objeto. Como duas posições opostas de inscrição do sujeito cabíveis no termo inicial sujet. Notamos com esta aproximação necessária entre os termos sujeito e objeto uma questão psicanalítica, pois toda noção da oposição sujeito-objeto, ou daquilo que não é sujeito ou não é objeto, é uma herança do campo da filosofia que se dedica ao estudo das relações entre ambos e, além disso, supõe o enrijecimento das mesmas. Portanto a dialética sujeito-objeto, enquanto herança filosófica, ganha valor significativo na pergunta sobre o sujeito.

Lacan implica os psicanalistas nesta diferenciação com o campo filosófico quando introduz a banda de Moebius como a figura que mostra o sujet. Como sabemos, podemos obter uma Banda de Moebius através de uma semi-torsão e posterior colagem das extremidades de uma fita qualquer. Nesta configuração, cria-se a ilusão perceptiva de que há dois lados e duas bordas. Mas, ao 
percorrermos longitudinalmente a linha média desta banda com a ponta de um lápis, revela-se que se trata de apenas uma borda e uma face. No entanto, esta indiferenciação é descoberta apenas ao se percorrer todo o percurso da banda. Ou seja: é apenas no percurso contínuo desta que ela ganha sua dimensão de superfície aberta. Em pontos isolados do percurso, ela segue apresentando uma aparente biparidade.

Em "A ciência e a Verdade", Lacan (1966/1998a) indica a divisão entre saber e verdade como "divisão experimentada do sujeito" (Lacan, 1966/1998a, p. 870). Então, em um momento originário, o saber e a verdade seriam uma unidade, pois, se há ao menos um que sabe, ele porta a verdade, o que ele sabe é certo. Para mostrar esse momento originário, Lacan propõe um cross-cap. É preciso situar a Banda de Moebius como efeito de um corte em um cross-cap, como é possível visualizar na figura a seguir.

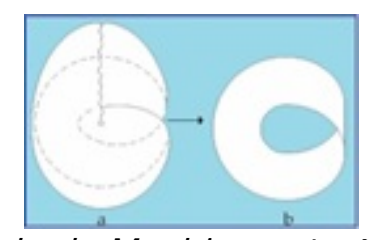

Figura 1: Uma Banda de Moebius extraída de um cross-cap.

(Lacan, 1965/1966, p. 35).

O paradoxo da Banda de Moebius é que para o observador externo há uma ilusão de que são dois lados (como os lados de uma folha: verso e anverso). No entanto, para um ser que percorre longitudinalmente a linha media dessa superfície, há apenas um lado. A posição de sujeito é o efeito de todo o trajeto, não apenas da descoberta de que a Banda de Moebius tem apenas um lado, mas também o trajeto que produz um corte no espaço. Ou seja, originariamente, a Banda de Moebius fazia parte de um espaço absoluto, sem cortes, o cross-cap. Esse corte é homólogo à extração de um saber a um Outro imaginário onisciente. $\mathrm{O}$ efeito desse corte é um sujeito posicionado em relação a esse saber. A Banda de Moebius, ao invés de definir o sujet, vai, através de seu percurso, mostrá-lo. Tomamos o ato de dizer, a fala, como sendo da mesma ordem: o significante divide o sujeito em dois, ele o representa e faz com que desapareça. Tal corte é o que produz a instância máxima do sujeito, o que desaparece justamente ao se representar, ao encontrar uma significação para o sujeito. É dizer, o sujeito é a dimensão que escapa à representação justamente quando se representa. Se nos recordarmos da definição do Real como o que não cessa de não se inscrever, sujeito e Real guardam uma particularidade importante em sua relação.

A atenuação da aparente disparidade entre dentro e fora como dois lados contrários de uma mesma face, de um mesmo lado, contradiz, através da psicanálise, a noção filosófica de dialética, onde uma coisa 
não é e nem pode ser outra coisa. É dizer, que a Banda de Moebius revela uma possibilidade de entendimento do psiquismo para além do ser ou não ser, e esta é propriamente a ideia inicial do significante linguístico: poder assumir vários significados, vários valores, através do mesmo significante.

Tal aproximação também vale para a dialética sujeito-objeto. O que aparentemente assume uma posição oposta uma da outra, ser sujeito ou ser objeto, pode ser visto como duas representações da mesma face, ou seja, estão do mesmo lado, sem disparidade.

Tomamos a ideia de que, ao percorrermos a linha média da banda, ora se ocupa a posição de sujeito ora de objeto, sem necessariamente haver uma contradição absoluta e sim uma referência significante. Este é o sujet de Lacan, que não está em oposição ao objeto: o que é objeto é o que ainda não é sujeito, mas desde o percurso da banda através da fala e do significante pode vir a ser. A forma como se percorre esta linha média, já sabemos: é através da fala. A fala é operativa do percurso pela Banda de Moebius, através dos significantes e das cadeias associativas em uma análise. Portanto, como saber se há posição de sujeito ou objeto sem a associação de significantes? Há sujet sem que se haja uma leitura de seu discurso, que se mostre e se ocupe dos percalços de sua fala, sem que se deixe levar pelo inconsciente? Ou há posição de objeto que não referido a uma posição também discursiva, sem ser lido?

No caso referido podemos notar a posição de objeto a que a paciente estava situada em seu tratamento psiquiátrico, reproduzindo uma lógica familiar onde sua posição de sujeito não era reconhecida. Neste caso obtemos exemplarmente a configuração de uma prática que sustenta um discurso enrijecido em seu saber sobre o outro do qual se vale como objeto, estando o sujeito fora, radicalmente excluído, foracluído da capacidade de saber sobre si. Na posição de objeto do saber psiquiátrico, lugar onde o sujeito não interfere, a paciente não encontrou alternativas senão se manter na posição de doente, confundindo-se com um diagnóstico de psicose. A ciência moderna como um saber sem sujeito é reproduzida nas formas psiquiátricas de diagnóstico nas quais as queixas são objetalizadas e não consideradas como mensagens cifradas.

A alternância de posições na dialética proposta pela teoria psicanalítica implica diretamente na escuta psicanalítica, pois pressupõe antecipadamente uma posição de sujeito implícita ao sintoma. Neste sentido, abrir a possibilidade para que o sujeito fale sobre si é dar voz à outra forma de situar seu sofrimento, conjugando enunciado e enunciação sem restringir as possibilidades de se representar senão como doente. $E$, nosso caso, até mesmo atuando na reavaliação de seu diagnóstico: não se tratava de uma psicose.

Substituindo a dialética por um trajeto sobre uma Banda de Moebius, podemos interpretar que a paciente encontrava nas automutilações 
uma forma de exercer algo de ordem sexual da qual estava impedida enquanto marcada pela insígnia do estupro outorgada pelos pais. Com os mesmos significantes que usava para falar das automutilações encontrou alternativas para sustentar uma posição de sujeito em relação à primeira relação sexual, da qual resultou uma gravidez: a dor, o corte, o sangue, entre outros.

Desta forma, a paciente pode sustentar minimamente seu erotismo, saindo da posição daquela que se automutilava para aquela que estava tentando elaborar uma cena para a qual um outro significante que o "estuprada" pudesse significar um sujeito. A escuta psicanalítica permitiu outras acepções de cortes, além dos cortes no sentido literal era possível pensar em cortes no sentido figurado.

Através disso o sofrimento ganhou novos termos, aliando-se ao que tinha a dizer sobre seus sintomas, fazendo emergir outras questões. Era o retorno do sujeito ao tratamento. Enquanto esteve em tratamento psicanalítico, mesmo estando sempre em evidência sua compulsão pelos cortes, a paciente pode dar outro destino aos mesmos e atenuar significativamente seu sintoma compulsivo, não havendo mais internação psiquiátrica.

A partir deste caso diferencia-se uma prática clínica que, ao enfocar o objeto da queixa, não consegue escutar o que se encobre no enunciado desta. Já a escuta psicanalítica, ao se perguntar pela posição do sujeito da cena fantasmática, permite outra leitura, com ampliação de sentido. Dessa maneira esta clínica reintroduz o sintoma na dimensão do inconsciente.

\section{Considerações Finais}

Os efeitos da foraclusão do sujeito no campo da ciência moderna são refletidos nas modalidades de clínica que sustentam os campos que se destinam ao estudo das psicopatologias. Consideramos que a prática que lida precisamente com as intermitências da fala considera o regresso do sujeito ao campo que foi criado através de sua exclusão. O reingresso deste sujeito que se faz ler em sua fala e na linguagem, através da psicanálise, no tratamento das psicopatologias convoca-nos a questionar a restrição inicial das posições estabelecidas que sustentam a própria condição de primazia do fenômeno sobre a fala do sujeito. Uma prática que se baseia em restrições de posições é impeditiva da emergência do sujeito que está para além do dito. Uma prática restritiva mantém posições inertes, o que por vezes pode acarretar na manutenção da ocorrência de sintomas graves fadados a nunca se deslocarem ou ganharem algum destino diverso. Apontamos com o caso relatado que uma prática que se ensurdeça à fala do sujeito não fornece possibilidades de aplacar os sintomas, objetivo inicial desta mesma prática. 


\section{Referências}

Chemama, R. (2000). Pourquoi Lacan dit-il que le sujet de la psychanalyse c'est le sujet de la science?. Bulletin de l'Association Freudienne International, 89, 7-10.

Damourette, J., \& Pichon, E. (1925). Grammaire et inconsciente. L'unebevue. Paris: E.P.E.L.

Freud, S. (2006a). História de uma neurose infantil. In Obras Psicológicas Completas de Sigmund Freud (Vol. 17, pp. 19129). Rio de Janeiro: Imago Editora. (Originalmente publicado em 1918[1914])

Freud, S. (2006b). A Negativa. In Obras Psicológicas Completas de Sigmund Freud (Vol. 19, pp. 265-269). Rio de Janeiro: I mago Editora. (Originalmente publicado em 1925)

Lacan, J. (1956). Le Seminaire. Livre 3. Les Psychoses - 1955-1956. Recuperado de www.staferla.free.fr

Lacan, J. (1966). Le Seminaire. Livre 13. L'Objet de la psychanalyse 1965-1966. Staferla. Recuperado de www.staferla.free.fr

Lacan, J. (1998a). A ciência e a verdade. In J. Lacan, Escritos (pp. 869-892). Rio de Janeiro: Jorge Zahar. (Originalmente publicado em 1966)

Lacan, J. (1998b). "Resposta ao comentário de Jean Hyppolite sobre a Verneinung de Freud", In J. Lacan, Escritos (pp. 383-401). Rio de Janeiro: Jorge Zahar. (Originalmente publicado em 1966).

Lacan, J. (1998c). "Subversão do sujeito e dialética do desejo no inconsciente freudiano", In J. Lacan, Escritos. (pp. 807-842). Rio de Janeiro: Jorge Zahar. (Originalmente publicado em 1966).

\section{Endereço para correspondência \\ Ricardo Bertazzo Ghilardi}

Universidade Federal do Rio Grande do Sul

Rua Ramiro Barcelos, 2600, Térreo, Santa Cecília, CEP 90035-003, Porto Alegre RS, Brasil

Endereço eletrônico: rbghilardi@gmail.com

\section{Marta Regina de Leão D'Agord}

Universidade Federal do Rio Grande do Sul

Rua Ramiro Barcelos, 2600, Térreo, Santa Cecília, CEP 90035-003, Porto Alegre RS, Brasil

Endereço eletrônico: marta.dagord@ufrgs.br

Recebido em: 29/10/2015

Reformulado em: 19/11/2016

Aceito em: 13/09/2018 


\section{Notas}

* Psicólogo, Especialista em Atendimento Clínico, Mestre em Psicologia Social e Institucional na Universidade Federal do Rio Grande do Sul.

** Psicóloga, Doutora em Psicologia (UFRGS). Pesquisadora Produtividade em Pesquisa 2 (CNPq). Professora Titular do Departamento de Psicanálise e Psicopatologia e do Programa de Pós-graduação em Psicanálise: Clínica e Cultura. Instituto de Psicologia. Universidade Federal do Rio Grande do Sul.

${ }^{1}$ Tradução livre de « le sujet de la Science va d'abord se définir en termes negatifs.

2

${ }^{2}$ Tradução livre de « c'est un sujet qui n'est pas à l'image du monde, un sujet qui ne se reconnait pas dans le monde »

3 Tradução livre de «la personne étoffée moi est donc suscetible, - point capital pour nous -, d'apparaître comme une constellation complexe d'où je soit extrayable.»

Financiamento: Capes-CNPQ.

Este artigo de revista Estudos e Pesquisas em Psicologia é licenciado sob uma Licença Creative Commons Atribuição-Não Comercial 3.0 Não Adaptada. 